\title{
Laboratory Simulation of Flow through Rough-Walled Microfractures under High Hydraulic Gradient
}

\author{
Shuai Zhang $\mathbb{D}^{1,2}$ Wei-Guo Qiao $\mathbb{D}^{1,2}$ Yan-Zhi Li $\mathbb{D}^{1,2}$ Wei-Jie Song, ${ }^{1,2}$ Jun-Ling Qin $\mathbb{D}$, ${ }^{1,2}$ \\ and Ji-Yao Wang ${ }^{1,2}$ \\ ${ }^{1}$ Shandong Provincial Key Laboratory of Civil Engineering Disaster Prevention and Mitigation, Shandong University of Science \\ and Technology, Qingdao, China \\ ${ }^{2}$ College of Civil Engineering and Architecture, Shandong University of Science and Technology, Qingdao, China
}

Correspondence should be addressed to Wei-Guo Qiao; qiaowg1@163.com

Received 4 August 2019; Accepted 9 September 2019; Published 10 October 2019

Academic Editor: Jaewon Jang

Copyright () 2019 Shuai Zhang et al. This is an open access article distributed under the Creative Commons Attribution License, which permits unrestricted use, distribution, and reproduction in any medium, provided the original work is properly cited.

\begin{abstract}
Laboratory experiments on fluid flow through fracture are important in solving the fluid-in-rush problems that happen during the tunnel excavation. In order to study the mechanism of fluid flow through a rough-walled microfracture, fluid flow experiments were carried out and the fiber Bragg grating (FBG) strain sensors were applied to monitor the deformation of the microfracture surface during the seepage process. Considering the difficulty of collection of undisturbed rock samples from the deep locations, a methodology to simulate fluid flow through a fractured rock mass using analog materials containing a single fracture was developed. This method is easy to simulate the fluid flow through a fracture of certain aperture. Experimental data showed that Forchheimer equation could provide an excellent description of the nonlinear relationship between hydraulic gradient and flow velocity, and the variations of Forchheimer coefficients with joint roughness coefficient (JRC) were studied. It was found that the deformation of the microfracture surface subjected to seepage could be accurately captured by the quasi-distributed FBG strain sensors. The test results also demonstrated that the surface strain is significantly affected by hydraulic pressure.
\end{abstract}

\section{Introduction}

The coupling effect of stress-seepage in fractured rock mass has played an increasingly important role in the geotechnical engineering activities, such as for construction of dam foundations, ore mineral extraction, water inrush prevention, and grouting activities [1-6]. Single fracture is the basic unit of rock mass fracture network, and its hydraulic characteristics affect the seepage law of rock mass [7-9]. To investigate this phenomenon, a number of theoretical models had been proposed, in which the cubic law is most popular. The cubic law considers that the fracture is composed of two ideal smooth, straight parallel plates. The flow of water in the fracture is a linear flow; therefore, the cubic law can be expressed as follows:

$$
Q=\frac{g}{v} \frac{\mathrm{we}^{3}}{12} J
$$

where $Q$ is the volumetric flow rate, $g$ is the gravitational acceleration, $v$ is the kinematic viscosity, $e$ is the hydraulic aperture of fracture, $w$ is the fracture width, and $J$ is the hydraulic pressure gradient along the flow direction.

In practice, rock fracture in realistic situations has very complicated geometric characteristics and obviously deviated from a parallel-plate model [10]. It has been found by researchers that fluid flow behavior through a rock mass is affected by many factors, such as the fracture geometry (width, density, aperture, orientation), fracture surface irregularities (roughness), fracture in-filling materials, fluid pressure, and confining pressure [11-14].

Many efforts have been made by earlier researchers to study the effect of roughness on fluid flow behavior through a rock mass described in the following. In the aspect of roughness, Barton and Quadros [15] conceptualized the relative roughness, which is defined as the function of the ratio between the maximum and minimum surface asperity height. Mandelbrot and Wheeler [16] proposed the concept 
of fractal geometry and fractal dimension, and analyzed the self-similarity of the rock fracture. Barton and Choubey [17] defined JRC and obtained 10 types of typical curves where JRC range from $0-2,2-4$, etc. up to $18-20$ from the many rock joint measurements. Xie and Pariseau [18] established the relationship between joint roughness and fractal dimension by the application of statistical methods. Furthermore, they found fractal dimension was significantly correlated with the value of JRC and established an expression between fractal dimension and JRC. Barton et al. [19] introduced JRC into the cubic law equation, which is simpler and quicker to obtain in the field and laboratory.

Experimental results of seepage tests conducted by Singh et al. [20] on single fractured granite specimens under triaxial stress conditions have shown that the fluid flow through single fracture in granite accords with Darcy's law or cubic law at high confining pressure and water pressure. However, fluid flow properties may not be modelled using cubic law because of the rough and irregular of fracture making contact with each other at discrete points could lead to the development of nonlinear flow. Sedghi-Asl et al. [21] studied the percolation behavior of six different sizes of rounded aggregates and reported that the flow deviates from Darcy conditions and enters into nonlinear flow conditions due to the increase of flow velocity and Reynolds number. Wang and Park [22] found the effects of stress and failure modes on axial permeability of five kinds of sandstone by triaxial compression tests and revealed that there is permeability reduction in the process of transition from brittle failure to plastic flow failure. Chen et al. [23] conducted a series of seepage tests for single fractured specimens under different confining stresses and established a quantitative relationship between fracture geometric characteristics parameters and fracture permeability.

However, most quantitative studies on stress-seepage coupling mechanism of single fractured rock mass focused on obtaining the seepage quantities or volumetric flow rate to analysis the seepage characteristics, not monitoring the deformation of the fracture during the seepage process due to the lack of suitable sensors. The traditional monitoring method is to use the resistance electronic sensor. However, the long-term stability of resistance electronic sensor is poor and it is difficult to achieve high accuracy measurement for the seepage pressure in fractured rock mass.

In recent years, a series of fiber optic sensing technologies have been developed rapidly, among which FBG sensing technology has made great progress in pressure, strain, and temperature monitoring. Compared with traditional sensors, FBG sensors have shown obvious advantages, such as their good insulation property, strong immunity to electromagnetic interference, good linearity and repeatability, high sensitivity and accuracy, excellent distributed monitoring ability, and long-term corrosion resistance; they are also small in size and lightweight. Zhu et al. [24] designed a slope monitoring system based on FBG sensing technology to monitor the displacement of slope and strains along soil nails. Huang et al. [25] carried out an experimental study on optical FBG sensing-based highway slope monitoring. In their study, a piezometer system had been developed using the optical
TABle 1: Physical properties of specimen.

\begin{tabular}{lccc}
\hline $\begin{array}{l}\text { Density } \\
\left(\mathrm{kg} / \mathrm{m}^{3}\right)\end{array}$ & $\begin{array}{c}\text { Compressive } \\
\text { strength}(\mathrm{MPa})\end{array}$ & $\begin{array}{c}\text { Modulus of } \\
\text { elasticity(MPa) }\end{array}$ & $\begin{array}{c}\text { Poisson's } \\
\text { ratio }\end{array}$ \\
\hline 1973 & 22.83 & 18,940 & 0.24 \\
\hline
\end{tabular}

FBG sensors and the monitoring data could evaluate the slope stability.

The article is aimed at solving the problems abovementioned using experimental methods, in order to better describe the seepage and deformation characteristics of rough-walled microfractures subjected to different confining and hydraulic stresses. With this idea, fluid flow experiments were conducted out on samples containing "single roughwalled microfracture." The aperture was $0.1 \mathrm{~mm}$, and the three JRC values were $0 \sim 2,4 \sim 6$, and 10 12. The experiments were conducted under varied conditions of confining pressure (4-10 MPa), with hydraulic pressure varied from 1 to $8 \mathrm{MPa}$. In addition, FBG sensors were fixed to the fracture surfaces of all the samples to characterize the fracture deformation quantitatively during the seepage process. Based on the experimental results, the nonlinear flow characteristics of samples with three different roughnesses were quantitatively evaluated. Further, the relationship between the variations of measured strain and the confining pressure (hydraulic pressure) was investigated.

\section{Experimental Methodology}

2.1. Sample Preparation. In this study, the specimens were made of cement, sand, gypsum, and water with a solid/water ratio of 5:1. The content of cement, sand, and gypsum by mass of solid was $20 \%, 70 \%$, and $10 \%$, respectively. The dimension of seepage specimen was $100 \times 100 \times 300 \mathrm{~mm}$, and the physical parameters are shown in Table 1.

The fracture surface was in the centre of the specimens, and steps were divided into two parts: preparation of core specimens and seepage specimens. The procedures were described below.

(1) Preparation of Core Specimens. Assembled the mould; the rough surface of the mould was used to generate the fracture surface; poured the materials into the mould to prepare core specimens, as shown in Figure 1.

(2) Installation of FBG Sensors. A fiber optic sensing array was adopted to monitor the strains of the fracture surface during seepage. The layout of the FBG sensors is shown in Figure 2(a). Table 2 shows the typical measuring parameters of the FBG sensing technology. The sensing array consists of a single-mode optical fiber containing five FBG sensors connected in a series, which was scanned by sm130 FBG demodulator controlled by a computer. During the installation, all of the sensors were carefully fixed at the prescribed location, as shown in Figure 2(b).

(3) Preparation of Seepage Specimens. After the sensors installed, the core specimens were combined. To create a fracture of a certain aperture, stainless steel belt of $0.1 \mathrm{~mm}$ 


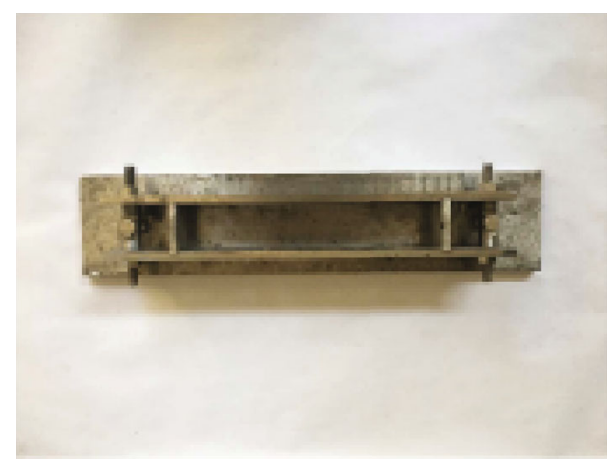

(a)

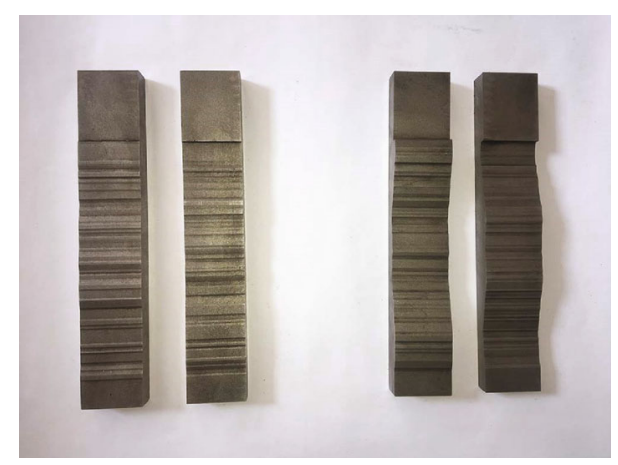

(b)

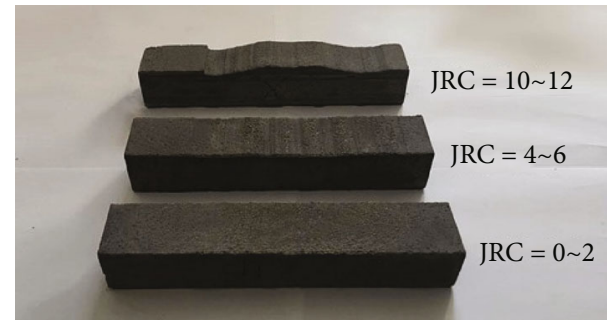

(c)

Figure 1: Preparation of core specimens: (a) core specimen mould, (b) rough surface mould, and (c) rough surface specimens.

thickness is used, as shown in Figure 3. Afterwards, put the specimens into mould and pour the materials to make seepage specimens, as shown in Figure 4 . After 24 hours of maintenance, remove the mould and pull out the stainless steel belt.

2.2. Experimental Instruments and Procedures. The fluid flow characteristic of the seepage sample containing a single fracture was determined using a triaxial stress-seepage mechanism model test system in the test, as shown in Figure 5. It consists of the triaxial high-pressure system $(\leq 60 \mathrm{MPa})$, the servocontrolled axial and circumferential loading system, the hydraulic system ( $\leq 30 \mathrm{MPa}$ ), the computer system (monitoring system), and other components. Besides, the sm130 fiber grating sensing demodulator produced by the Micron Optics Company was used to collect the strain on the surface of the fracture during the seepage process. The strain values of different measuring points are real-time displayed in the computer system. The test procedures are described below

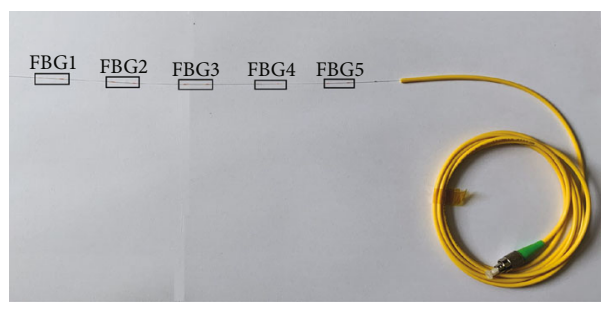

(a)

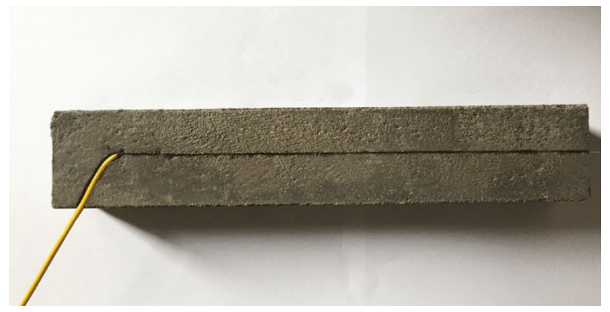

(b)

FIGURE 2: Details of the FBG sensors in the core specimen: (a) layout of the FBG strain sensing sensors and (b) installation of FBG sensors.

TABLE 2: Typical parameters of the FBG technology.

\begin{tabular}{lccc}
\hline $\begin{array}{l}\text { Wavelength } \\
\text { range }(\mathrm{nm})\end{array}$ & $\begin{array}{c}\text { Wavelength } \\
\text { repeatability }(\mathrm{pm})\end{array}$ & $\begin{array}{c}\text { Scan frequency } \\
(\mathrm{Hz})\end{array}$ & $\begin{array}{c}\text { Strain } \\
\text { range }(\mu \varepsilon)\end{array}$ \\
\hline $1510-1590$ & 1 & 1000 & $\begin{array}{c}-3000- \\
3000\end{array}$ \\
\hline
\end{tabular}

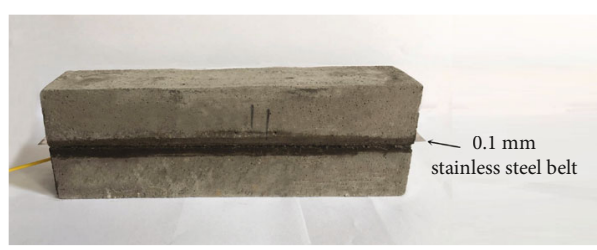

FIGURE 3: Combination of the core specimens.

(Figure 6(a)), and the test loading scheme is showed in Figure 6(b).

To prevent water from leaking from the fracture to rock matrix during seepage test, each specimen was firstly soaked in distilled water until saturation. Afterwards, the saturated sample was taken out and put it into the seepage trial cell. After the test equipment system debugging, the trial cell was loaded with the initial axial pressure of $0.5 \mathrm{MPa}$ to prevent any undesirable displacements of the specimen. The sequence of load applied to the sample is as follows. First, the axial force is applied to the predetermined load $(10 \mathrm{MPa})$ and the trial cell was filled with hydraulic oil and settled with the initial confining stress of $4 \mathrm{MPa}$. Second, seepage pressure is applied by the hydraulic system until the initial seepage stress is $1 \mathrm{MPa}$. Then, the confining stress increases with an increment of $1 \mathrm{MPa}$ in the range from $4 \mathrm{MPa}$ to $10 \mathrm{MPa}$. Finally, the seepage stress increases with an increment of $1 \mathrm{MPa}$ in the range from $1 \mathrm{MPa}$ to $8 \mathrm{MPa}$. Besides, the amount of water flowing from the outlet (discharge, Q) was collected in a container. The container was 


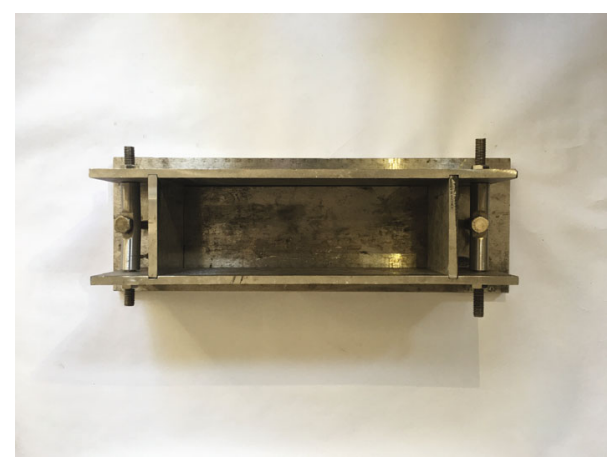

(a)

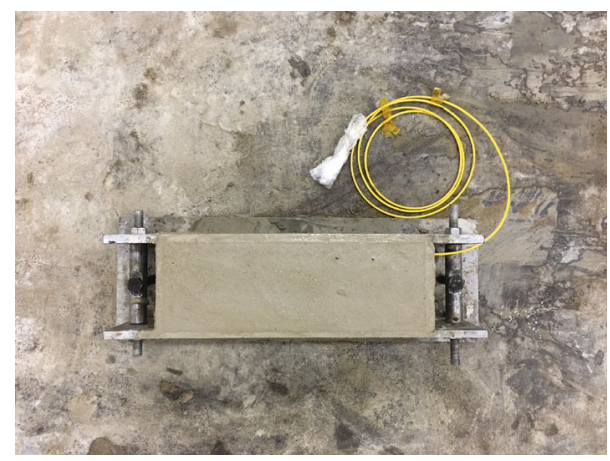

(b)

FIGURE 4: Preparation of seepage specimens: (a) seepage specimen mould and (b) seepage specimen.

placed over an electronic balance of $1200 \mathrm{~g}$ capacity. During the seepage test, the fracture surface strain and the discharge $Q$ were recorded at every $3 \mathrm{~s}$ interval.

\section{Results and Discussion}

3.1. Nonlinear Flow Characteristics under Different JRC. Experimental results of the samples have been analyzed, and the curves in the form of the hydraulic pressure $P$ versus the discharge $Q$, corresponding to confining stress $\sigma_{3}$ of $10 \mathrm{MPa}$, have been plotted for samples with $\mathrm{JRC}=0 \sim 2,4 \sim 6$, and $10 \sim 12$, as shown in Figure 7 . It can be observed from the figure that the increase in $P$ leads to an increase in $Q$; however, the increase of JRC values obviously decreases the Q. This can be attributed to the fact that the less tortuous path of flow in case of sample (JRC $=0 \sim 2)$ compared to its counterparts (JRC $=4 \sim 6$ and 10 12) causes resistance decrease in flow through the fracture. For samples with different JRC , most of the measured experimental data deviate from the linear relationship between $P$ and $Q$, indicating that the flow through the microfracture does not follow Darcy's law and cubic law which assumes that linear flow between two parallel smooth plates and different nonlinear flow characteristics begin to take place. This deviation in the flow can be a result of significant inertial effect or fracture dilation. The results are consistent with previous literature $[23,26]$.

The curves in the form of the hydraulic gradient $J$ versus the flow velocity $V$ for samples with different JRC are shown in Figure 8. It can be observed that the relationship between $J$ and $V$ obtained from each test deviates from the linear rela-

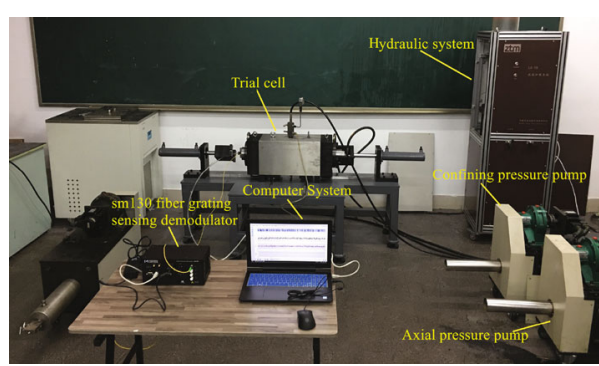

FIgURE 5: Test equipment system.

tionship, indicating that the linear Darcy's law is no longer suitable for describing the relationship between $V$ and $J$. It can be seen that the $J-V$ relation shifts downwards as the JRC values increase, indicating lower flow resistance. Hence, the greater the JRC is, the greater hydraulic gradient it will require to obtain a same flow velocity, as has been reported in the literature [27].

In order to further study seepage in rough fractures under high hydraulic gradient, the Forchheimer equation is introduced to analyze the experimental data and describe the nonlinear flow characteristics quantitatively. Forchheimer's law provides a general relation including the nonlinear effect, which can account for the nonlinear characteristics of the hydraulic gradient versus discharge $[28,29]$. The Forchheimer equation can be expressed as follows:

$$
J=a V+b V^{2}
$$

where $a$ and $b$ are the Forchheimer coefficients expressing the nonlinear effect due to viscous and inertial dissipation mechanisms. The regression analyses were performed on the experimental data in the form of Forchheimer's equation, and the regression coefficients $a$ and $b$ for all cases are summarized in Table 3. The correlation coefficient $R^{2}$ for each sample is more than 0.98 , indicating that Forchheimer's law could better describe the nonlinear fluid flow through rough-wall fractures. It can be observed from Table 3 that coefficients $a$ and $b$ increase with the increases in joint roughness, whereas coefficient $a$ does not indicate an obvious correlation with $b$. The JRC values from $0 \sim 2$ to $4 \sim 6$ result, generally, in an increase of coefficients $a$ and $b$ by a factor of 4.15 and 73, respectively. However, the JRC values from $0 \sim 2$ to $10 \sim 12$ result in a significant increase of $a$ and $b$ by a factor of 38.23 and 1353.53, respectively. It can be concluded that, as the JRC values increase, the effect of inertial force becomes more and more significant.

The Reynolds number Re, which defines the flow as laminar or turbulent is important for studying the fluid flow characteristics through fractured rock mass, can be calculated using the following equation:

$$
\mathrm{Re}=\frac{\rho Q}{\mu W},
$$

where $\rho$ is the fluid density, $Q$ is the discharge, $\mu$ is the dynamic viscosity of fluid, and $W$ is the fracture width. 


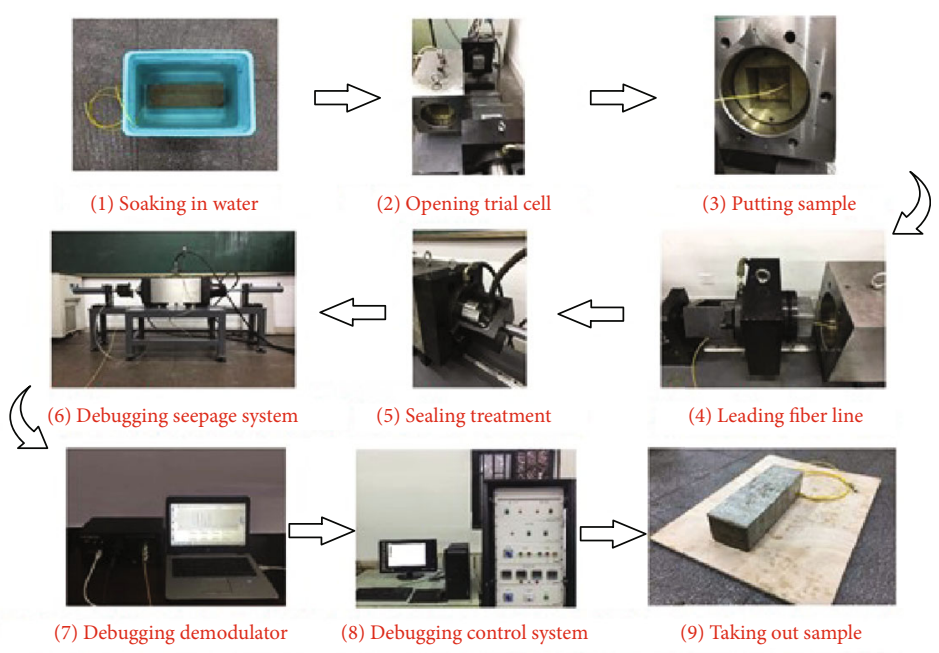

(a)

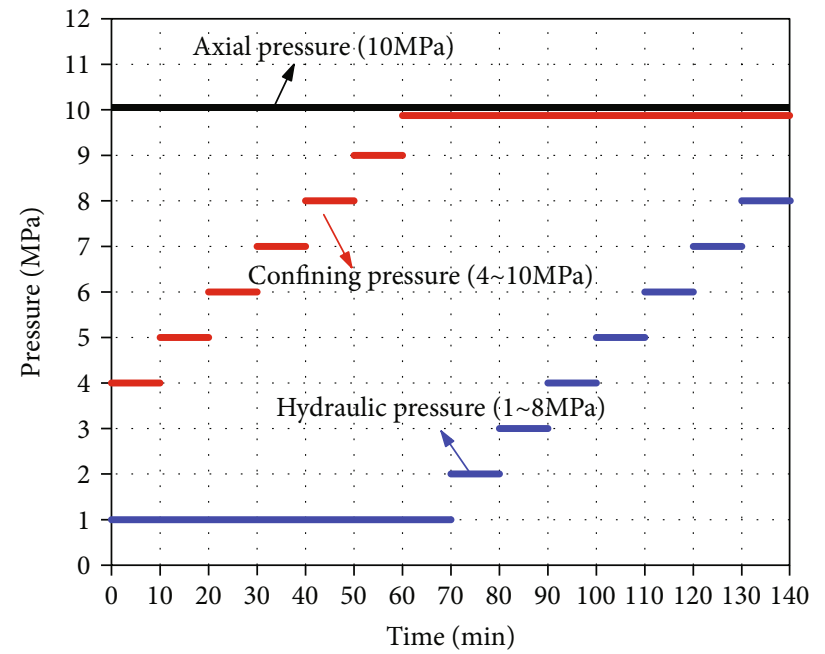

(b)

FIGURE 6: Experimental methods: (a) test procedures and (b) loading scheme.

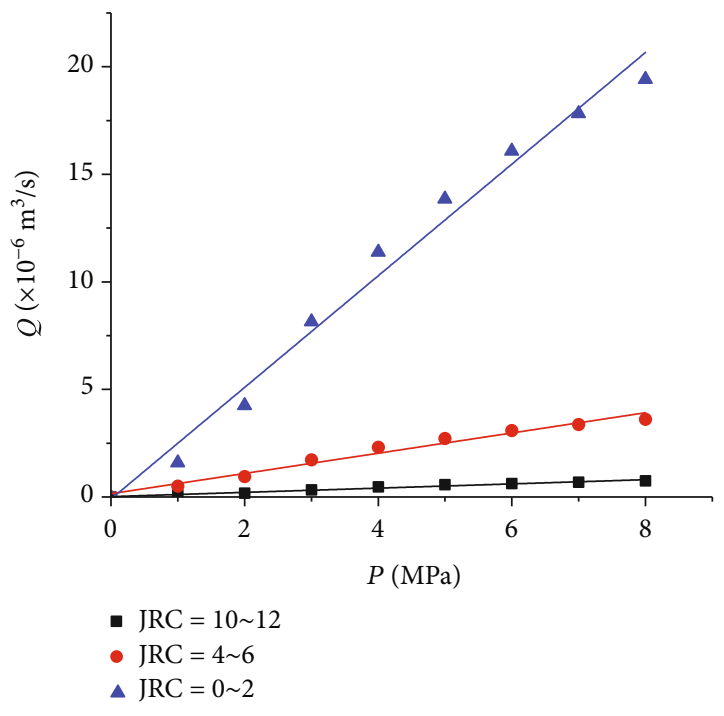

FIGURE 7: The measured and corresponding fitted curves in the form of $Q$ versus $P$ for samples with different JRC.

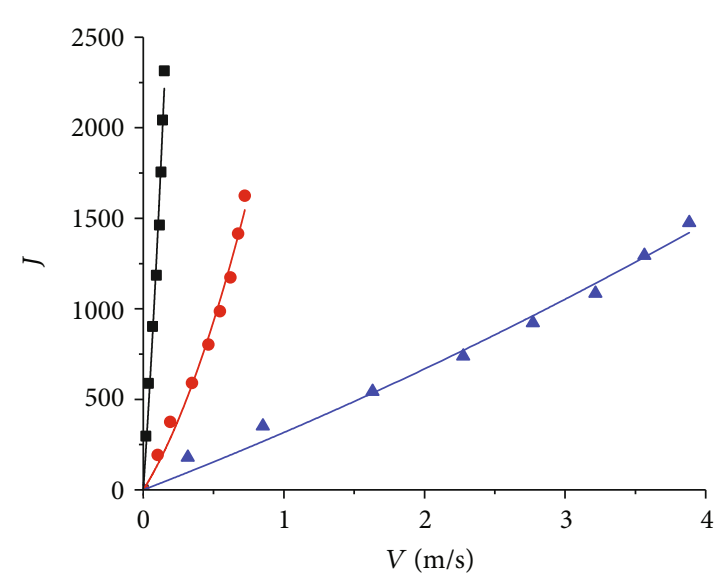

- $\mathrm{JRC}=10 \sim 12$

- $\mathrm{JRC}=4 \sim 6$

$\triangle \mathrm{JRC}=0 \sim 2$

Figure 8: Relationship between hydraulic gradient $J$ and flow velocity $V$ at different JRC. 
TABLE 3: Fitting results of Forchheimer equation of rough fracture under different JRC.

\begin{tabular}{lcccc}
\hline Aperture $/ \mathrm{mm}$ & JRC & $a\left(\mathrm{~s} \cdot \mathrm{m}^{-1}\right)$ & $b\left(\mathrm{~s}^{2} \cdot \mathrm{m}^{-2}\right)$ & $R^{2}$ \\
\hline 0.1 & $0 \sim 2$ & 299 & 17 & 0.9846 \\
0.1 & $4 \sim 6$ & 1242 & 1241 & 0.9886 \\
0.1 & $10 \sim 12$ & 11,430 & 23,010 & 0.9863 \\
\hline
\end{tabular}

TABLE 4: Values of Reynolds number Re for all test cases.

\begin{tabular}{lcc}
\hline $\operatorname{Re}(J R C=0 \sim 2)$ & $\operatorname{Re}(J R C=4 \sim 6)$ & $\operatorname{Re}(J R C=10 \sim 12)$ \\
\hline 31.7676 & 10.2664 & 1.7434 \\
85.0364 & 19.1768 & 3.6804 \\
163.0992 & 34.6732 & 6.586 \\
227.602 & 46.2954 & 9.2978 \\
277.192 & 54.431 & 11.4286 \\
321.55 & 61.9854 & 12.5908 \\
356.416 & 67.4092 & 13.753 \\
388.378 & 72.2518 & 14.9152 \\
\hline
\end{tabular}

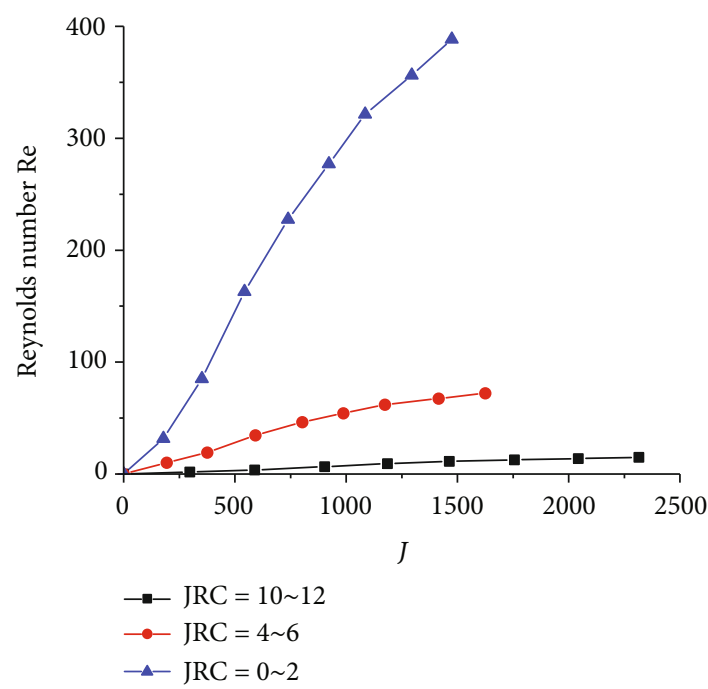

FIGURE 9: The variation of Re with $J$ corresponding to different JRC.

The Reynolds number values were calculated according to Equation (2) and are depicted in Table 4. It can be observed that as expected, Re is quite sensitive to $J$ and a nonlinear relationship exists between Re and $J$. Hassanizadeh and Gray [30] found the critical Reynolds number $(\mathrm{Re}=10)$ of the transition from laminar flow to turbulent. It can be observed from Table 4 that most of the experimental data for all the test sample falls exceed the critical Reynolds number $\operatorname{Re}>10$. This result indicates that the fluid flow was in the state of turbulence. Furthermore, we plotted the variation of Reynolds number Re with hydraulic gradient $J$ for samples with different JRC values, as shown in Figure 9. It can be observed from Figure 9 that as the hydraulic gradient increases, the Reynolds number value increases, whereas the increasing rate gradually decreases. Moreover, the Reynolds number values decrease with the increase of the JRC values under the same hydraulic gradient and fracture aperture,

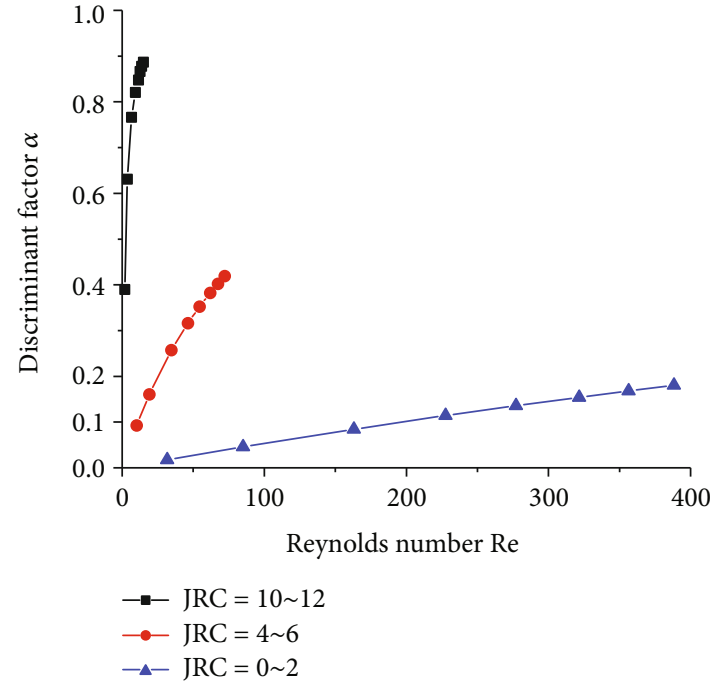

Figure 10: Relationship between discriminant factor $\alpha$ and the Reynolds number Re.

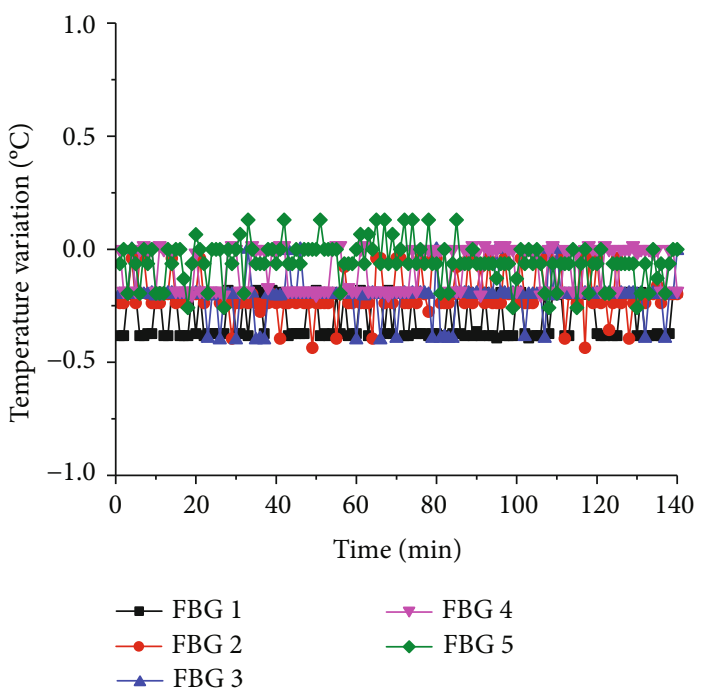

FIGURE 11: Temperature variation measured by the FBG sensors.

which indicating higher flow resistance. In case of microfracture with a small aperture, the effect of surface roughness on fluid flow is significant, and hence, lower JRC values and thereby larger Re $>10$ can be obtained.

Although the fluid behavior of fluid flow through a single rough-walled fracture has been studied, but there is a limit on the occurrence of a fully developed turbulent regime in rough-walled fractures. In order to quantitatively evaluate the nonlinear effect of fluid flow in rock seepage process, a discrimination parameter $\alpha$ was proposed, as expressed as follows:

$$
\alpha=\frac{b V^{2}}{a V+b V^{2}}
$$

where $a V$ and $b V^{2}$ are the head loss caused by the viscous force and the inertia force, respectively. For the case of $\alpha=0$, 


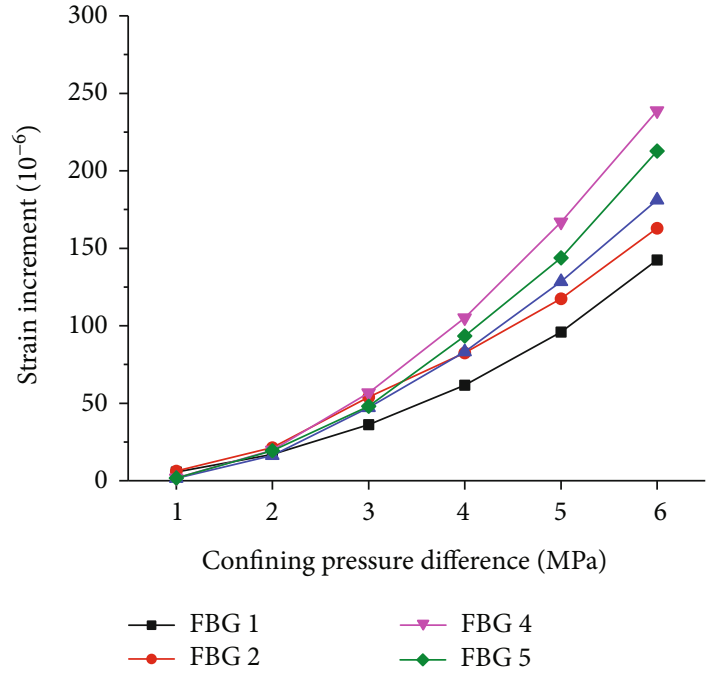

(a)

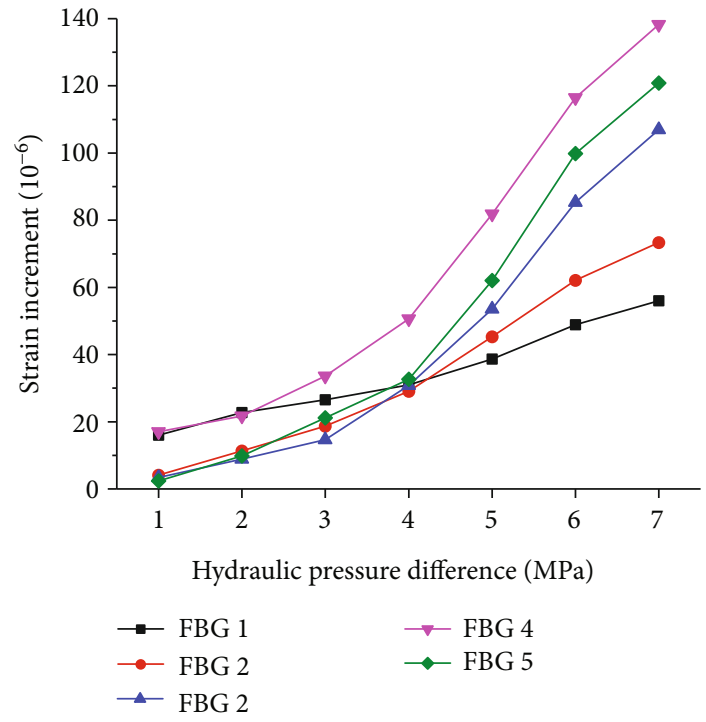

(b)

FIGURE 12: Strain monitoring results of microfracture surface with JRC $=0 \sim 2$ : (a) relationship between strain measured at different points and confining pressure difference and (b) relationship between strain measured at different points and hydraulic pressure difference.

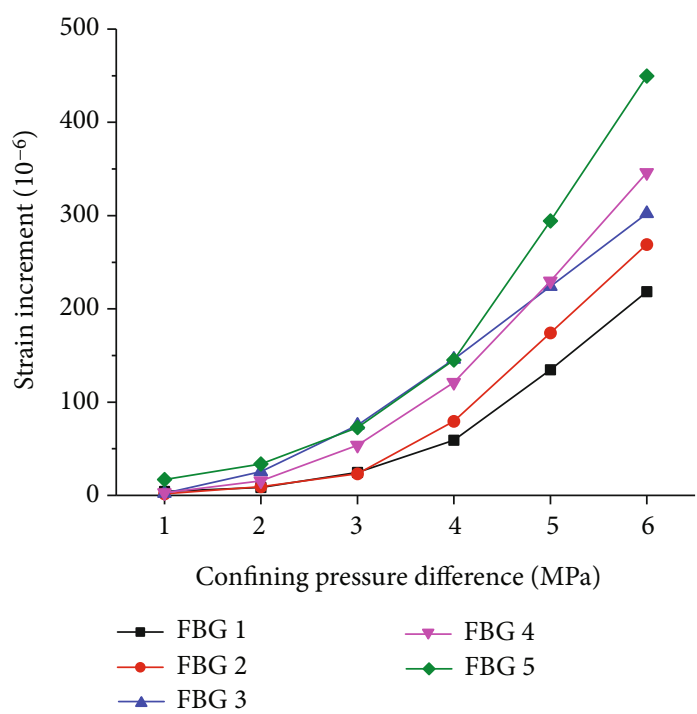

(a)

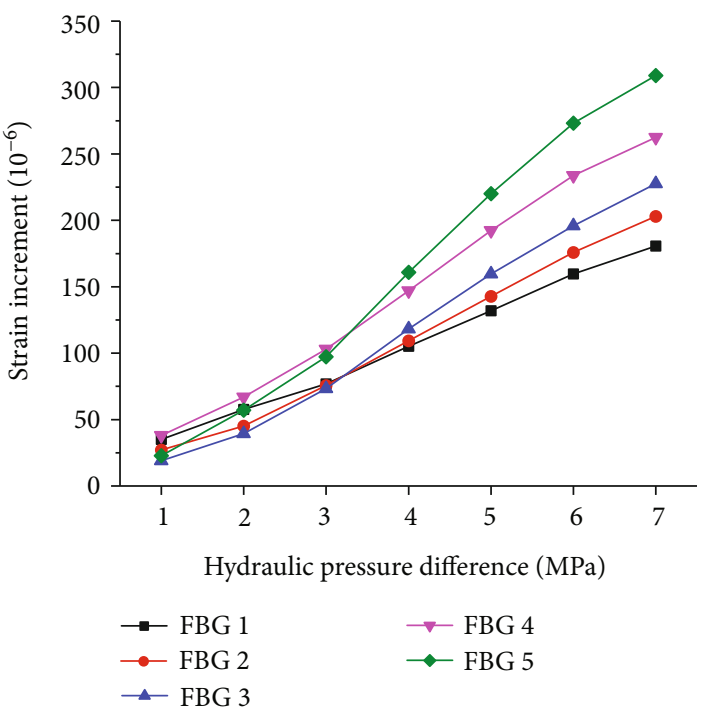

(b)

FIGURE 13: Strain monitoring results of microfracture surface with JRC $=4 \sim 6:$ (a) relationship between strain measured at different points and confining pressure difference and (b) relationship between strain measured at different points and hydraulic pressure difference.

the inertia force can be neglected; therefore, Darcy's law can be used to describe the fluid flow through fractured rockmass. For $\alpha=1$, this indicates that the fluid flow was in the fully developed turbulence. To quantitatively estimate the nonlinear behavior of fluid flow through single rough-walled fracture, Zimmerman and Yeo [31] determined a critical value $\alpha=0.1$ ( $10 \%$ of the overall head loss) to distinguish the Darcy flow state and weak nonlinear flow state for engineering application. According to Table 4 and Equation (4), we calculated the discrimination parameter $\alpha$, and the relationship between the discrimination parameter $\alpha$ and Reynolds number Re is shown in Figure 10. It can be observed that most of the discrimination factors are larger than 0.1 , which indicates the fluid flow through single rough-walled fracture under the high hydraulic gradient shows nonlinear regimes. However, when the JRC is $0 \sim 2$, the factor $\alpha$ ranges from $0.018 \sim 0.18$, indicating a weak nonlinear flow regime. Zhou et al. [32] and Xia et al. [33] proposed a discriminant factor $\alpha=0.9$ to divide the turbulent regime into two categories: weak turbulence and fully developed turbulence. Therefore, it can be concluded that the fluid flow through a single rough-walled fracture shows a weak turbulence in this study. This finding can be attributed to that a high surface roughness corresponds to a small fracture aperture and larger flow resistance 


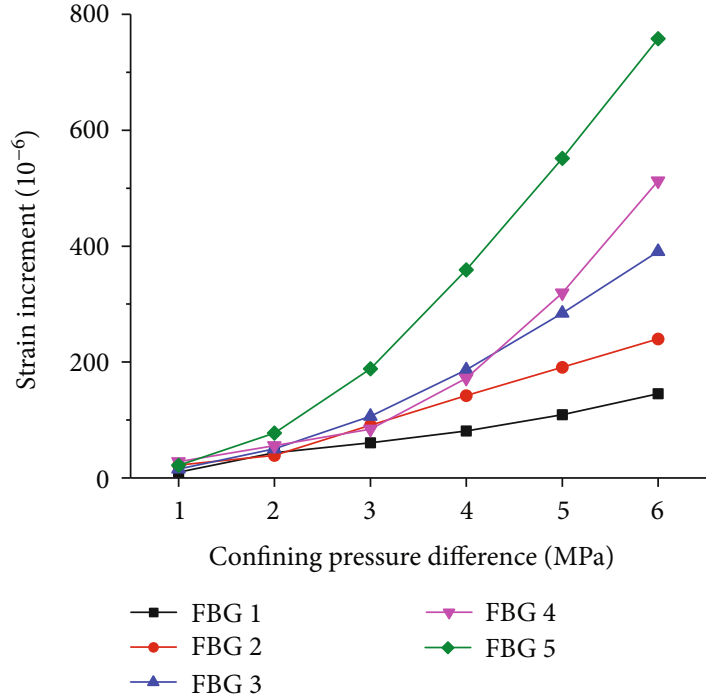

(a)

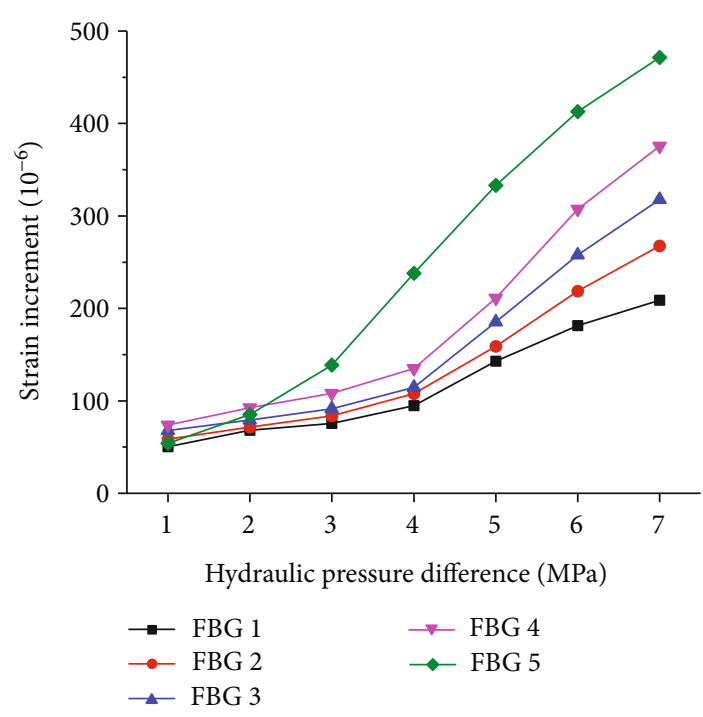

(b)

FIGURE 14: Strain monitoring results of microfracture surface with JRC $=10 \sim 12$ : (a) relationship between strain measured at different points and confining pressure difference and (b) relationship between strain measured at different points and hydraulic pressure difference.

and thus results in a small Reynolds number, thereby indicating that the fluid flow through microfracture shows weak turbulent regime.

\subsection{Characteristics of Strain Variation during the Seepage} Process. Figure 11 shows the monitoring results of the FBG sensors. It can be observed that the temperature variation during the seepage test was minor (within $1.0^{\circ} \mathrm{C}$ ). Therefore, the nonuniformity in the temperature distribution inside of the model was little and the significance of temperature compensation for strain measurement was negligible.

In order to further explore the deformation characteristics of fracture during the seepage test, the strain monitoring results of the FBG sensors that were embedded in the fracture surface with different JRC values are shown in Figures 12-14.

It can be seen from Figures 12-14(a) that when the axial pressure is $10 \mathrm{MPa}$ and the hydraulic pressure is $1 \mathrm{MPa}$, there is a significant increase of strain increment with the increase of confining pressure difference, and the growth trend is in the form of quadratic parabola. The increase in the strain indicates that the fracture surface was subjected to compression, mainly due to the high confining pressure. The comparison between the five FBG sensors shows that the response of the FBG 5 sensor was the quickest (as the water first touched it), and the strain increment was also the largest due to the largest hydraulic pressure. When JRC values are 4 6 and $10 \sim 12$, the locations of maximum strain increment are both FBG 5 sensor, and the corresponding strain increment is $450 \times 10^{-6}$ and $758 \times 10^{-6}$, respectively. However, when JRC value is $0 \sim 2$, the location of maximum strain increment is FB4 sensor, which may be due to the different degrees of contact in different positions. From the above results, it can be concluded that the impact of the confining pressure is mainly on the stress state of the sample, and the effect of surface roughness on strain increment during the seepage process is also important.

As seen in Figures 12-14(b), when the axial pressure is $10 \mathrm{MPa}$ and the confining pressure is $10 \mathrm{MPa}$, the strain increment of the five FBG sensors grows with the increase of the hydraulic pressure difference. During the rising of the hydraulic pressure difference, there is a slight increase of the strain increment, followed by a faster growth in the later stage. Therefore, the fracture surface strain grows with the increase of hydraulic pressure, and the fracture aperture increased. This phenomenon is called the "expanding fracture effect," as reported in the available literature [34]. Because of the different compaction degrees of the fracture, the variation of strain is not obvious when the hydraulic pressure is small. However, with the increase of hydraulic pressure, a part of the compacted fracture will gradually reopen, the seepage field in the fracture will be redistributed, and the strain increment of the five points will show a rapidly rising tendency. It can be concluded that high hydraulic pressure could lead to the addition and enlargement of microfractures and enhance the connectivity between seepage fractures, thus forming more water conduction channels, leading to water inrush accidents.

\section{Conclusions}

Based on the experimental results obtained and within limited ranges of parameters studied in this research, the following conclusions can be drawn:

(1) Nonlinear fluid flow behavior was observed from the relationship between the hydraulic gradient and average velocity. Forchheimer's law could provide an excellent description of the non-Darcy flow characteristics caused by inertia effect in single microfracture with different roughness 
(2) The coefficients $a$ and $b$ of Forchheimer's equation increased with the increase in surface roughness for each sample, and the growth rate increased significantly. Moreover, the increase rate of $a$ is much lower than that of $b$

(3) The factor $\alpha$ is used to estimate the nonlinear characteristics, and all the $\alpha$ factors are larger than the critical value of $\alpha=0.1$, which is used to determine the start point of nonlinear fluid flow

(4) The FBG sensors have the advantages of quasidistributed sensing and of being lightweight and small-sized, and the modeling of seepage monitoring indicated that this method works well to measure the strains of microfracture surface

(5) The variations of the strains inside the model subjected to seepage had been captured, which provide an improved insight into the deformation pattern associated with water seepage in rock mass

\section{Data Availability}

The data used to support the findings of this study are included within the article.

\section{Conflicts of Interest}

The authors declare that there are no conflicts of interest regarding the publication of this paper.

\section{Acknowledgments}

This research was funded by the National Key Research and Development Program, China (Grant No. 2016YFC0600902), the National Natural Science Foundation of China, China (Grant Nos. 51474135, 51774192, and 51704183), the SDUST Research Fund (Grant No. 2015TDJH104), and the Postgraduate Technology Innovation Project of Shandong University of Science and Technology (Grant No. SDKDYC190239).

\section{References}

[1] G. Wang, K. Wang, S. Wang, D. Elsworth, and Y. Jiang, “An improved permeability evolution model and its application in fractured sorbing media," Journal of Natural Gas Science and Engineering, vol. 56, pp. 222-232, 2018.

[2] X.-X. Yang and W.-G. Qiao, "Numerical investigation of the shear behavior of granite materials containing discontinuous joints by utilizing the flat-joint model," Computers and Geotechnics, vol. 104, pp. 69-80, 2018.

[3] C. Yan, Y.-Y. Jiao, and H. Zheng, "A fully coupled threedimensional hydro-mechanical finite discrete element approach with real porous seepage for simulating 3D hydraulic fracturing," Computers and Geotechnics, vol. 96, pp. 73-89, 2018.

[4] X. Z. Lyu, Z. Zhao, X. Wang, and W. Wang, "Study on the permeability of weakly cemented sandstones," Geofluids, vol. 2019, Article ID 8310128, 14 pages, 2019.

[5] Q. Y. Zhang, K. Duan, Y. Y. Jiao, and W. Xiang, "Physical model test and numerical simulation for the stability analysis of deep gas storage cavern group located in bedded rock salt formation," International Journal of Rock Mechanics and Mining Sciences, vol. 94, pp. 43-54, 2017.

[6] C. Yan and Y.-Y. Jiao, "A 2D fully coupled hydro-mechanical finite-discrete element model with real pore seepage for simulating the deformation and fracture of porous medium driven by fluid," Computers \& Structures, vol. 196, pp. 311-326, 2018.

[7] X. L. Zhang, Y. Y. Jiao, and J. Zhao, "Simulation of failure process of jointed rock," Journal of Central South University of Technology, vol. 15, no. 6, pp. 888-894, 2008.

[8] F. Ye, J.-C. Duan, W.-X. Fu, and X.-Y. Yuan, "Permeability properties of jointed rock with periodic partially filled fractures," Geofluids, vol. 2019, Article ID 4039024, 14 pages, 2019.

[9] S.-Q. Yang, H.-W. Jing, Y.-H. Huang, P. G. Ranjith, and Y.Y. Jiao, "Fracture mechanical behavior of red sandstone containing a single fissure and two parallel fissures after exposure to different high temperature treatments," Journal of Structural Geology, vol. 69, pp. 245-264, 2014.

[10] J. Zhang, L. Yu, H. Jing, and R. Liu, "Estimating the effect of fractal dimension on representative elementary volume of randomly distributed rock fracture networks," Geofluids, vol. 2018, Article ID 7206074, 13 pages, 2018.

[11] Q. Zhang, S. Luo, H. Ma, X. Wang, and J. Qian, "Simulation on the water flow affected by the shape and density of roughness elements in a single rough fracture," Journal of Hydrology, vol. 573, pp. 456-468, 2019.

[12] A. P. S. Selvadurai, "Normal stress-induced permeability hysteresis of a fracture in a granite cylinder," Geofluids, vol. 15, no. 1-2, 47 pages, 2015.

[13] B. Li, Y. Jiang, T. Koyama, L. Jing, and Y. Tanabashi, "Experimental study of the hydro-mechanical behavior of rock joints using a parallel-plate model containing contact areas and artificial fractures," International Journal of Rock Mechanics and Mining Sciences, vol. 45, no. 3, pp. 362-375, 2008.

[14] G. He, E. Wang, and X. Liu, "Modified governing equation and numerical simulation of seepage flow in a single fracture with three-dimensional roughness," Arabian Journal of Geosciences, vol. 9, no. 1, p. 81, 2016.

[15] N. Barton and E. F. de Quadros, "Joint aperture and roughness in the prediction of flow and groutability of rock masses," International Journal of Rock Mechanics and Mining Sciences, vol. 34, no. 3-4, pp. 252.e1-252e.14, 1997.

[16] B. B. Mandelbrot and J. A. Wheeler, "The fractal geometry of nature," American Journal of Physics, vol. 51, no. 3, p. 286, 1983.

[17] N. Barton and V. Choubey, "The shear strength of rock joints in theory and practice," Rock Mechanics and Rock Engineering, vol. 10, no. 1-2, pp. 1-54, 1977.

[18] H.-P. Xie and W. G. Pariseau, "Fractal estimation of joint roughness coefficients," Science in China (Series B), vol. 37, no. 12, pp. 1516-1524, 1994.

[19] N. Barton, S. Bandis, and K. Bakhtar, "Strength, deformation and conductivity coupling of rock joints," International Journal of Rock Mechanics and Mining Sciences \& Geomechanics Abstracts, vol. 22, no. 3, pp. 121-140, 1985.

[20] K. K. Singh, D. N. Singh, and P. G. Ranjith, "Laboratory simulation of flow through single fractured granite," Rock Mechanics and Rock Engineering, vol. 48, no. 3, pp. 987-1000, 2015.

[21] M. Sedghi-Asl, H. Rahimi, and R. Salehi, "Non-Darcy flow of water through a packed column test," Transport in Porous Media, vol. 101, no. 2, pp. 215-227, 2014. 
[22] J.-A. Wang and H. D. Park, "Fluid permeability of sedimentary rocks in a complete stress-strain process," Engineering Geology, vol. 63, no. 3-4, pp. 291-300, 2002.

[23] Y. Chen, W. Liang, H. Lian, J. Yang, and V. P. Nguyen, "Experimental study on the effect of fracture geometric characteristics on the permeability in deformable rough-walled fractures," International Journal of Rock Mechanics and Mining Sciences, vol. 98, pp. 121-140, 2017.

[24] H.-H. Zhu, A. N. L. Ho, J.-H. Yin, H. W. Sun, H.-F. Pei, and C.-Y. Hong, "An optical fibre monitoring system for evaluating the performance of a soil nailed slope," Smart Structures and Systems, vol. 9, no. 5, pp. 393-410, 2012.

[25] A.-B. Huang, J.-T. Lee, Y.-T. Ho, Y.-F. Chiu, and S.-Y. Cheng, "Stability monitoring of rainfall-induced deep landslides through pore pressure profile measurements," Soils and Foundations, vol. 52, no. 4, pp. 737-747, 2012.

[26] X.-D. Nie, Y.-L. Niu, Y. Wang, and K. Yu, "Non-Darcy flow experiments of water seepage through rough-walled rock fractures," Geofluids, vol. 2018, Article ID 8541421, 12 pages, 2018.

[27] X. Qian, C. Xia, Y. Gui, X. Zhuang, and Q. Yu, "Study on flow regimes and seepage models through open rough-walled rock joints under high hydraulic gradient," Hydrogeology Journal, vol. 27, no. 4, pp. 1329-1343, 2019.

[28] C. Zhu, X. Xu, X. Wang et al., "Experimental investigation on nonlinear flow anisotropy behavior in fracture media," Geofluids, vol. 2019, Article ID 5874849, 9 pages, 2019.

[29] Q. Yin, H. Jing, R. Liu, G. Ma, L. Yu, and H. Su, "Experimental study on stress-dependent nonlinear flow behavior and normalized transmissivity of real rock fracture networks," Geofluids, vol. 2018, Article ID 8217921, 16 pages, 2018.

[30] S. M. Hassanizadeh and W. G. Gray, "High velocity flow in porous media," Transport in Porous Media, vol. 2, no. 6, pp. 521-531, 1987.

[31] R. W. Zimmerman and I.-W. Yeo, "Fluid flow in rock fractures: from the Navier-Stokes equations to the cubic law," Dynamics of Fluids in Fractured Rock, vol. 122, pp. 213-224, 2000.

[32] J.-Q. Zhou, S.-H. Hu, Y.-F. Chen, M. Wang, and C.-B. Zhou, "The friction factor in the Forchheimer equation for rock fractures," Rock Mechanics and Rock Engineering, vol. 49, no. 8, pp. 3055-3068, 2016.

[33] C.-C. Xia, X. Qian, P. Lin, W. M. Xiao, and Y. Gui, "Experimental investigation of nonlinear flow characteristics of real rock joints under different contact conditions," Journal of Hydraulic Engineering, vol. 143, no. 3, p. 04016090, 2017.

[34] Y. Zhang, Y. Ma, Z. Hu et al., “An experimental investigation into the characteristics of hydraulic fracturing and fracture permeability after hydraulic fracturing in granite," Renewable Energy, vol. 140, pp. 615-624, 2019. 

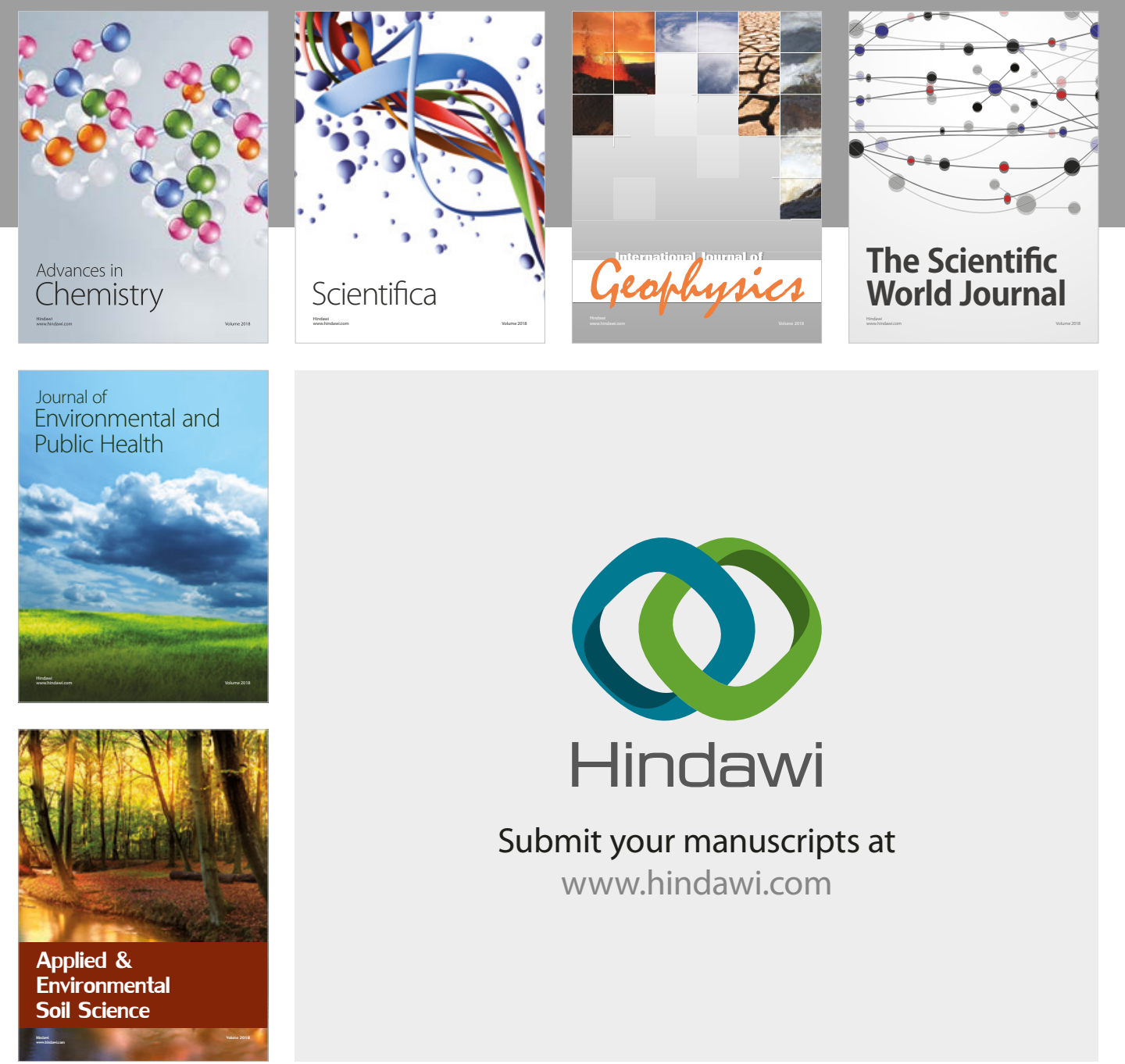

The Scientific

\section{World Journal}
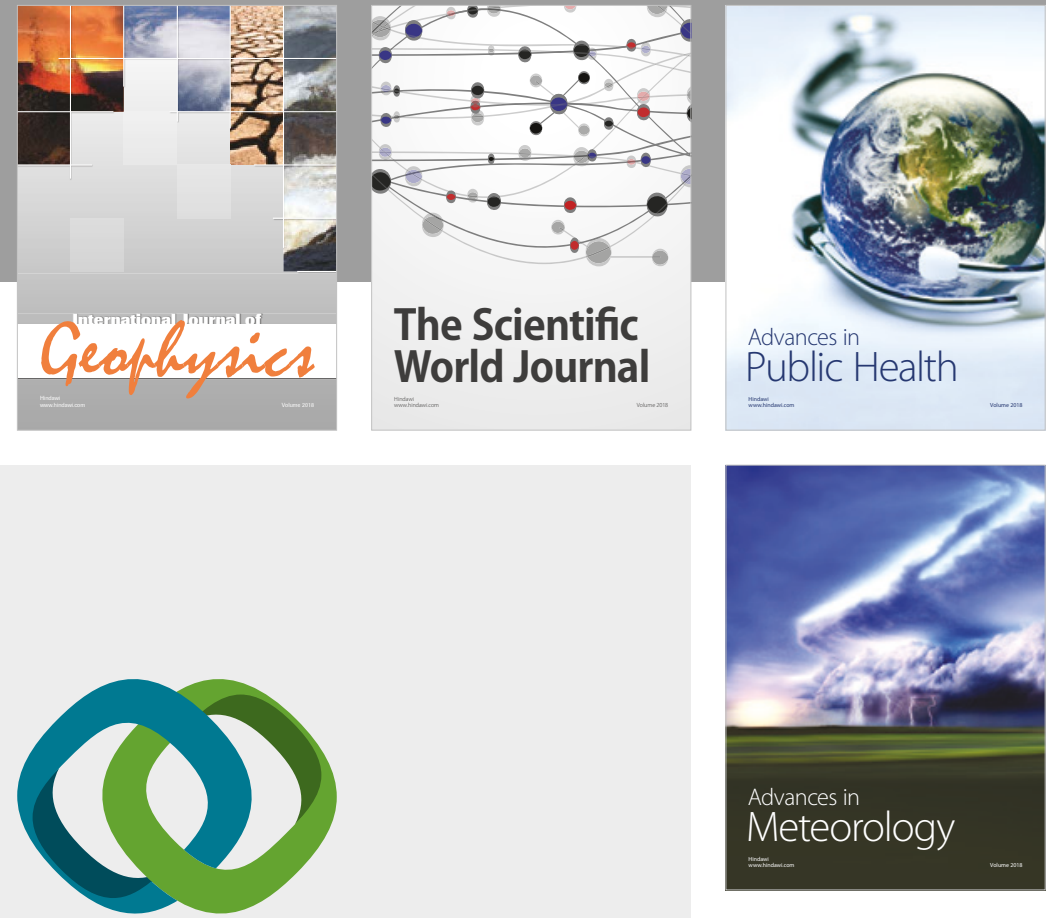

Advan

Public Health

\section{Hindawi}

Submit your manuscripts at

www.hindawi.com
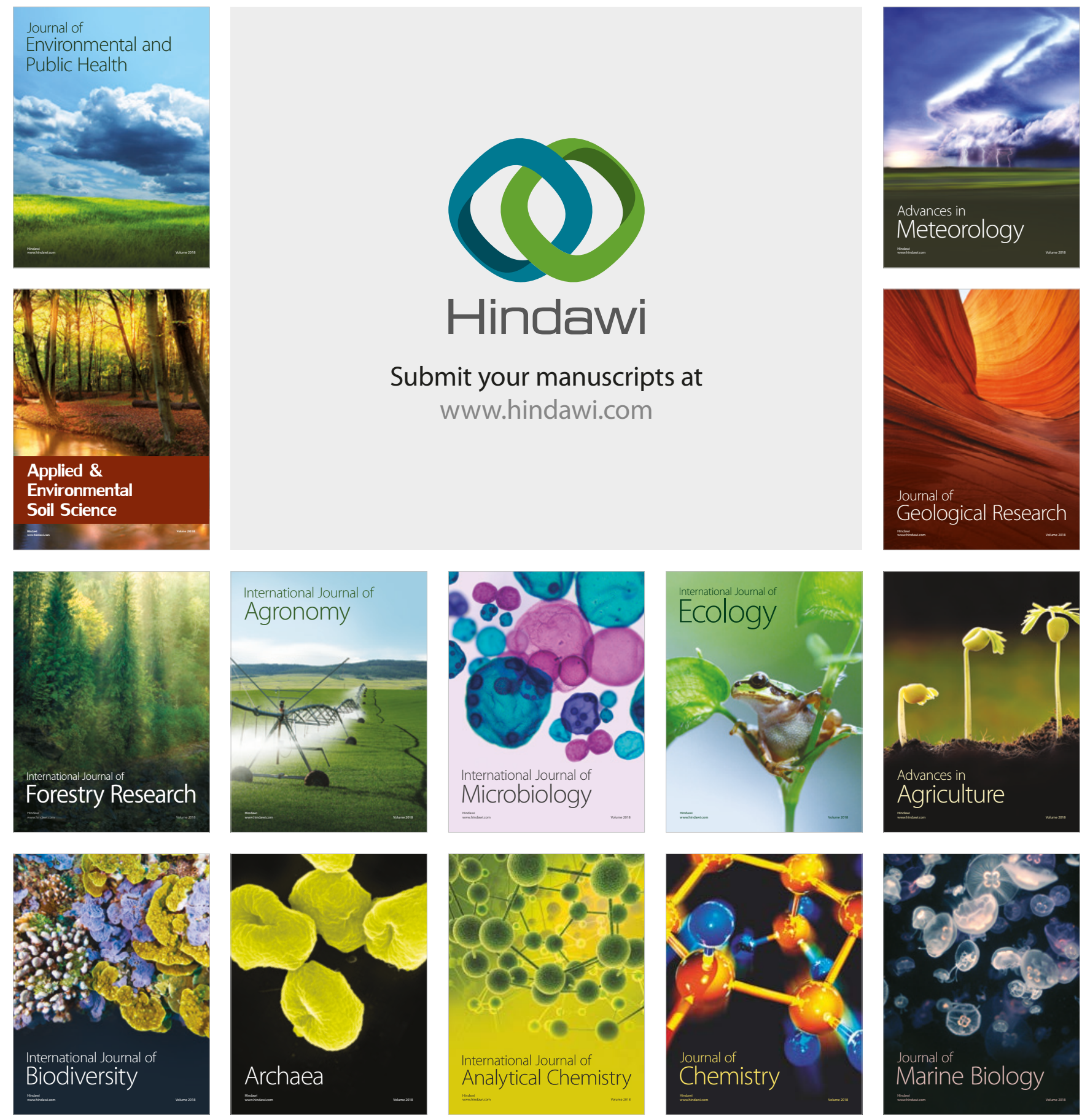